\title{
Clinical use of lenvatinib in combination with everolimus for the treatment of advanced renal cell carcinoma
}

\section{Alessandro Leonetti \\ Francesco Leonardi Melissa Bersanelli Sebastiano Buti}

Medical Oncology Unit, University Hospital of Parma, Parma, Italy
Correspondence: Sebastiano Buti Medical Oncology Unit, University Hospital of Parma, Via Gramsci I4, 43।26, Parma, Italy

Tel +390521 702316

Email sebabuti@libero.it
This article was published in the following Dove Press journal:

Therapeutics and Clinical Risk Management

30 June 2017

Number of times this article has been viewed

Introduction: Renal cell carcinoma (RCC) represents $2 \%-3 \%$ of all cancers in adults, and its pathogenesis is mainly related to altered cellular response to hypoxia. Lenvatinib, a novel multitarget tyrosine kinase inhibitor (TKI), represents a therapeutic option, in combination with mammalian target of rapamycin (mTOR) inhibitor everolimus, for the treatment of metastatic RCC (mRCC).

Aim: The objective of this article is to review the evidence about the treatment of mRCC with combination of lenvatinib plus everolimus.

Evidence review: Phase I studies supported clinical activity of lenvatinib in mRCC. A randomized, Phase II, open-label, multicenter trial demonstrated the clinical efficacy of combination treatment with lenvatinib plus everolimus in patients with progressive $\mathrm{mRCC}$ after prior therapy with TKI. Median progression-free survival was improved by 9 months with the combination therapy compared to the single-agent everolimus, with an overall response rate of $43 \%$ for the experimental regimen. Lenvatinib plus everolimus appeared to be slightly less toxic than singleagent lenvatinib and more toxic than single-agent everolimus; grade 3-4 adverse events occurred in $71 \%$ of patients. Currently, lenvatinib plus everolimus has US Food and Drug Administration approval for its use in $\mathrm{mRCC}$ after failure of previous treatment with TKI.

Conclusion: The combination therapy with lenvatinib plus everolimus might be a promising choice for second-line treatment of mRCC patients. Based on the results of the Phase II trial, it is possible to speculate that the combination therapy could be appropriate for patients with high disease burden or strongly symptomatic patients.

Keywords: lenvatinib, everolimus, evidence-based review, renal cell carcinoma, RCC

\section{Introduction}

Renal cell carcinoma (RCC) represents 2\%-3\% of all cancer, and its incidence has increased by $\sim 2 \%$ worldwide over the two last decades. ${ }^{1}$ The most common histotype is represented by clear cell RCC (ccRCC), accounting for $70 \%-85 \%$ of sporadic RCC; less frequent variants include papillary $(7 \%-15 \%)$ and chromophobe RCC $(5 \%-10 \%){ }^{2}$ $\mathrm{RCC}$ is often diagnosed incidentally when undergoing abdominal imaging for other reasons, ${ }^{3}$ and it occurs as metastatic disease at diagnosis in about one third of patients. ${ }^{4}$ Usually, surgery is the initial treatment for both local and locally advanced disease; however, for most patients with advanced tumor, systemic therapy is needed. ${ }^{1,5}$

Recent advances in the understanding of tumor biology and of pathogenetic mechanisms have led to the development of new drugs for the management of metastatic disease, including new targeted therapies, such as tyrosine kinase inhibitors (TKIs), mammalian target of rapamycin (mTOR) inhibitors, and programmed death-1 (PD-1)/ 
programmed death ligand-1 (PD-L1) immune checkpoint inhibitors. $^{6}$

TKIs are small molecules that inhibit key pathways involved in RCC cell growth and proliferation, cellular metabolism, and angiogenesis, such as vascular endothelial growth factor (VEGF), platelet-derived growth factor (PDGF), and mTOR pathways. Until recently, four TKIs were available for the treatment of metastatic RCC (mRCC): sunitinib, which targets VEGF and PDGF receptors (VEGFR and PDGFR, respectively), c-KIT, and FMS-like tyrosine kinase-3 (FLT-3); pazopanib, a selective inhibitor of VEGFRs, PDGFR, and c-KIT ${ }^{8}$ axitinib, which inhibits VEGFR-1, VEGFR-2, and VEGFR- $3{ }^{9}{ }^{9}$ and sorafenib, a multi-inhibitor of Raf-1 serine/threonine kinase, BRAF, VEGFR-2, PDGFR, FLT-3, and c-KIT. ${ }^{10}$ According to current European Society of Medical Oncology guidelines, sunitinib and pazopanib are recommended for the first-line treatment of recurrent, metastatic, or inoperable RCC with good-intermediate prognosis; axitinib and sorafenib are approved for their use after failure of first-line therapy. Interferon- $\alpha$ plus bevacizumab, an anti-VEGF-A monoclonal antibody, represent another option for the management of mRCC with good-intermediate prognostic features in first-line setting. Among mTOR inhibitors, temsirolimus and everolimus have shown activity in $\mathrm{mRCC}$ : temsirolimus is recommended for the first-line therapy of poor prognosis ccRCC or non-ccRCC, whereas everolimus is a treatment option for second and subsequent lines. ${ }^{2}$

Until recently, the standard treatment for advanced ccRCC after first-line TKI failure was represented by axitinib or everolimus; sorafenib was reserved only for selected cases. Two new molecules, cabozantinib and nivolumab, have shown superiority over everolimus in terms of overall survival (OS) and response rate (RR) in secondline setting for mRCC in two comparative head-to-head Phase III trials. ${ }^{11,12}$ Based on these results, cabozantinib and nivolumab are preferred choices over everolimus in secondline therapy. ${ }^{2,13}$

Lenvatinib (E7080, Lenvima ${ }^{\circledR}$; Eisai, Hatfield, UK) is a multitarget kinase inhibitor firstly approved by US Food and Drug Administration (FDA) and European Medicine Agency (EMA) as monotherapy for the treatment of locally recurrent or metastatic, progressive, radioactive iodinerefractory differentiated thyroid cancer, and more recently approved by FDA, in combination with everolimus, for the treatment of advanced RCC following one prior antiangiogenic therapy. This review discusses the mechanism of action, pharmacokinetics, clinical efficacy, and tolerability of lenvatinib in combination with everolimus for the treatment of advanced RCC.

\section{Mechanism of action}

Two pivotal molecular events are involved in the pathogenesis of ccRCC: the loss of function of von Hippel-Lindau (VHL) gene that acts as a tumor-suppressor gene and the consequent overexpression of hypoxia-inducible factors (HIF). The protein encoded by VHL gene is responsible for HIF expression downregulation by degrading HIF-1 $\alpha$ subunit. The reduced activity of VHL gene results in constitutively activated hypoxic response even in the absence of a hypoxic signal, ${ }^{14}$ leading to the transcription of HIF-responsive genes, such as VEGF, PDGF, and transforming growth factor beta (TGF- $\beta) .{ }^{15}$ This event is crucial in RCC carcinogenesis; overexpressed growth factors induce pathogenic angiogenesis, tumor growth, and cancer progression in addition to their normal cellular functions. ${ }^{16}$

The second critical pathway involved in the development and growth of RCC is regulated by mTOR protein. The mTOR signaling pathway is known to be responsible for anchorage-independent cellular expansion, increased proliferative potential and evasion from apoptosis, and increased cell motility and metastasis. ${ }^{17}$ Moreover, the activation of mTOR induced by overexpressed growth factors (ie, VEGF and PDGF) promotes HIF expression, ${ }^{18,19}$ triggering a positive feedback loop between VHL/HIF and mTOR signaling. ${ }^{20}$ It is evident that the two pathways are closely connected and cross-talking, hence the attempt of combining both TKI and the mTOR inhibitors for the treatment of mRCC.

In the past, randomized trials have been conducted trying to combine VEGF and mTOR inhibitors, with poor results on efficacy outcomes and increased drug toxicity. Combinations of temsirolimus plus bevacizumab, temsirolimus plus sorafenib, and everolimus plus bevacizumab were also investigated, with disappointing results. ${ }^{21-23}$

Lenvatinib is a novel potent multitarget TKI that performs its action through the inhibition of VEGFR-1, VEGFR-2, VEGFR-3, PDGFR- $\beta$, RET, c-KIT, and fibroblast growth factor receptors (FGFR) 1-4, the latter deemed as responsible for resistance to VEGF inhibitors in RCC. ${ }^{24,25}$ Preclinical data on the effect of the combination of lenvatinib with everolimus have been reported. Matsumi et al investigated the mechanisms of these drugs used in combination in human RCC xenograft mouse models: everolimus demonstrated antiproliferative effects, whereas lenvatinib showed antiangiogenic properties. In this study, tumor angiogenesis was evaluated by microvessel density (MVD) of the tumor; whereas lenvatinib monotherapy consistently reduces MVD 
in A-498 xenografts, everolimus monotherapy did not. In the same xenograft model, enhanced antitumor activity resulted from the combination of the two drugs, suggesting the synergistic effect of the two different mechanisms of action.

It is evident that targeting tumor cell growth and angiogenesis through the combination of lenvatinib plus everolimus can result in enhanced antitumor activity (Figure 1). ${ }^{26}$

A strong rationale to combine two molecules with different mechanism of action (Figure 1), the good tolerability profile of everolimus in $\mathrm{mRCC}$ patients and the availability of preclinical data that showed the synergistic antitumor effect of these two drugs, all together are elements that justify the choice to further develop the combination of everolimus (instead of other agents) with lenvatinib in the clinical setting.

\section{Pharmacokinetics}

Lenvatinib is orally administered. The peak of its concentration $\left(\mathrm{C}_{\max }\right)$ is reached within 3 hours from administration and it increases linearly with dose increase, as observed in two Phase I dose-escalation studies investigating pharmacokinetics of the drug administered at escalation doses of $0.2 \mathrm{mg}$ up to $32 \mathrm{mg}$ per day and $0.5 \mathrm{mg}$ bid up to $20 \mathrm{mg}$ bid. No accumulation after multiple once-daily dose was observed. ${ }^{27,28}$ In subjects with adequate renal and hepatic function, $\mathrm{C}_{\max }$ and systemic exposure (as measured by area under the curve [AUC]) do not vary under fasting conditions (AUC ratio fed/ fasted of 1.00 [90\% confidence interval $\{\mathrm{CI}\}$ 0.82-1.20]; $\mathrm{C}_{\max }$ ratio fed/fasted of 0.98 [90\% CI 0.73-1.31]), but an effect of food on time to maximal plasma concentration $\left(\mathrm{t}_{\max }\right)$ was observed, with a shift from 2 hours in the fasted group to 5 hours in the fed group, resulting in delayed absorption following a standard high-fat meal. ${ }^{28}$ The terminal volume of distribution of orally administered lenvatinib varies from 50.5 to $163 \mathrm{~L}$, and terminal half-life $\left(\mathrm{t}_{1 / 2}\right)$ is $\sim 28$ hours. $^{29}$ Lenvatinib is highly bound to plasma proteins and metabolized into many metabolites, mainly in the liver; low levels of unchanged lenvatinib were found in urine and feces. ${ }^{30}$ The principal isoform of cytochrome involved in hepatic metabolism of lenvatinib is CYP3A4, which is responsible for $>80 \%$ of the CYP-mediated metabolism of the drug. ${ }^{31}$

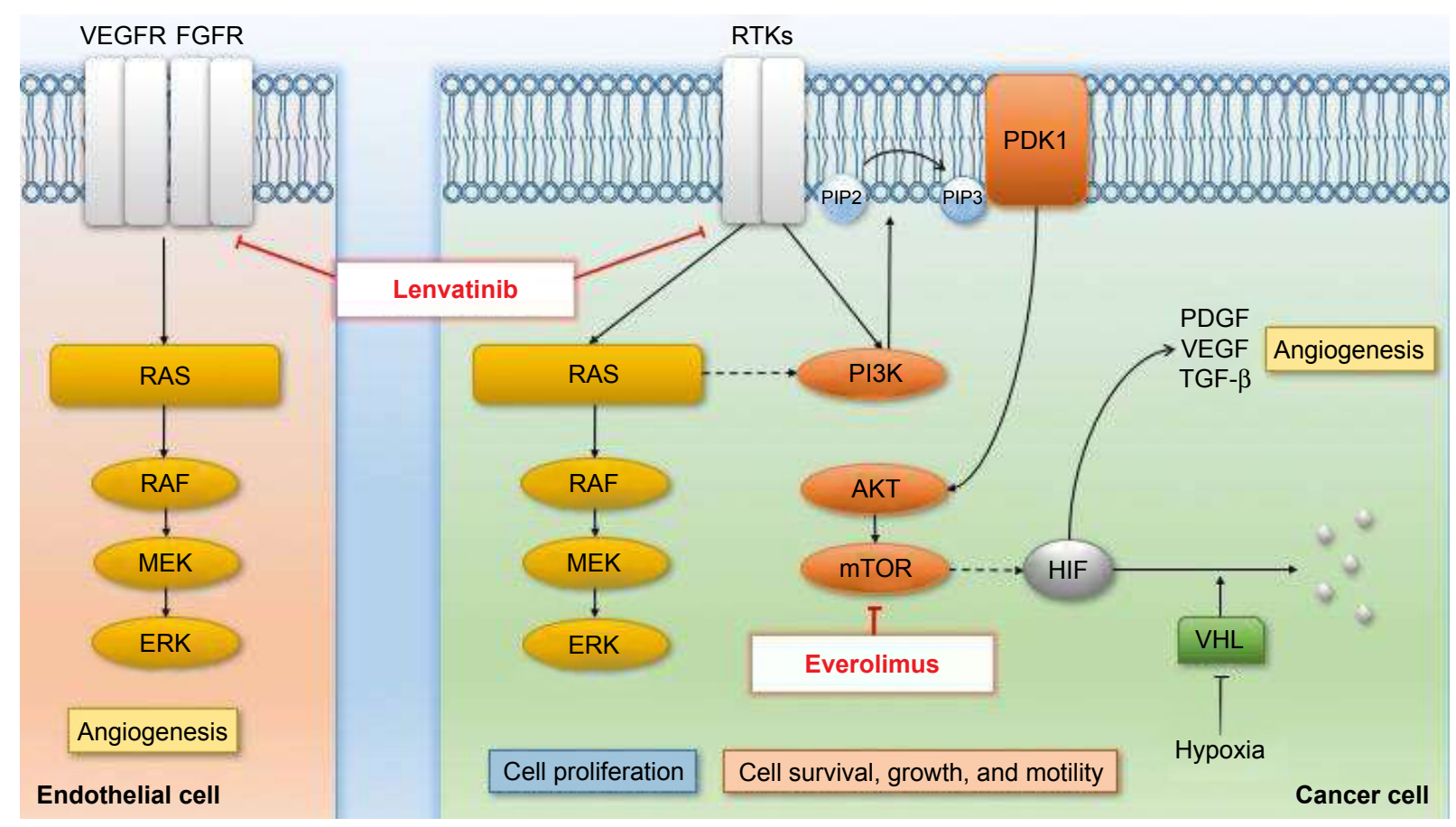

Figure I Mechanisms of action of lenvatinib and everolimus.

Notes: Lenvatinib inhibits RTKs on endothelial cell and cancer cell. Activated VEGFR and FGFR on endothelial cell trigger the MAPK/ERK pathway that promotes angiogenesis. On cancer cell, activated RTKs (ie, VEGFR, PDGFR- $\beta$, RET, c-KIT, and FGFR) mediate cell proliferation through the MAPK/ERK pathway; the activation of PI3K/AKT/mTOR pathway leads to cell survival, growth, and motility. Everolimus inhibits mTOR signaling. HIF is degraded by VHL in normoxic condition; in the presence of hypoxia, or when overexpressed, it promotes angiogenesis through the synthesis of growth factors. Dashed arrows indicate crosslinks between different signaling pathways: RAS activates PI3K, whereas mTOR promotes HIF expression.

Abbreviations: VEGF, vascular endothelial growth factor; PDGF, platelet-derived growth factor; TGF- $\beta$, transforming growth factor beta; VEGFR, vascular endothelial growth factor receptor; PDGFR, platelet-derived growth factor receptor; FGFR, fibroblast growth factor receptor; RTK, receptor tyrosine kinase; MAPK, mitogen-activated protein kinase; ERK, extracellular signal regulated kinase; PI3K, phosphoinositide 3-kinase; mTOR, mammalian target of rapamycin; HIF, hypoxia-inducible factor; VHL, von Hippel-Lindau; PDK, pyruvate dehydrogenase kinase; RAS, rat sarcoma; RAF, rapidly accelerated fibrosarcoma; MEK, mitogen-activated protein extracellular signal-regulated kinase kinase; ERK, extracellular signal-regulated kinase; PIP, phosphatidylinositol phosphate; AKT, protein kinase B kinase (AKT8 virus oncogene cellular homolog). 
Two drug-interaction studies by Shumaker et al have been conducted to test the pharmacokinetic parameters of lenvatinib when coadministered with CYP3A4 or P-gp inhibitors (rifampicin and ketoconazole, respectively). Lenvatinib exposure was increased by CYP3A4 or P-gp inhibition, but the magnitude of change was not clinically meaningful. ${ }^{32,33}$

Pharmacokinetics was studied also in special populations. The average AUC of lenvatinib in 12 subjects with mild or moderate hepatic impairment increased by $170 \%$ compared to the AUC found in eight healthy volunteers, and $t_{1 / 2}$ increased from 23 to 37 hours, suggesting dose adjustments for patients with hepatic dysfunction. ${ }^{34}$ Impaired renal function and the concomitant administration of everolimus in patients affected by mRCC seem to not affect the pharmacokinetic properties of lenvatinib. When lenvatinib was administered at a dose of $18 \mathrm{mg}$ in combination with everolimus $5 \mathrm{mg}$, oral clearance and volume of distribution as a function of bioavailability did not vary compared to lenvatinib $24 \mathrm{mg}$; AUC of lenvatinib $28 \mathrm{mg}$ in combination with everolimus $5 \mathrm{mg}$, dose-normalized to $24 \mathrm{mg}$, was similar to the AUC of single-agent lenvatinib at a dose of $24 \mathrm{mg} .^{29,35}$

\section{Clinical efficacy and safety}

Clinical trials of efficacy and safety of lenvatinib alone or in combination with everolimus in advanced RCC are shown in Table 1.

\section{Phase I evidence}

Preliminary evidence of antitumor activity of lenvatinib in patients with advanced solid tumors was provided by a Phase I, dose-escalation study by Yamada et al. Twentyseven patients affected by different histological types of solid tumors, refractory to conventional therapies or for which there was no available effective therapy, were treated with

Table I Clinical trials of efficacy and safety of lenvatinib in renal cell carcinoma

\begin{tabular}{|c|c|c|c|c|}
\hline Clinical trial & Design & Arms & Efficacy & Safety \\
\hline Boss et $\mathrm{al}^{28}$ & $\begin{array}{l}\text { Phase } \mathrm{I} \text {, dose-escalation } \\
\mathrm{n}=82 \text { (different histologic } \\
\text { tumor types) } \\
\text { mRCC patients }=9\end{array}$ & $\begin{array}{l}\text { Lenvatinib, starting from } \\
0.2 \mathrm{mg} \text { daily }\end{array}$ & $\begin{array}{l}\text { mPFS (for RCC patients): } 447 \text { days } \\
\text { ORR: } \\
\text { Overall population: } 55 \% \\
\text { mRCC patients: } 4 / 9 \text { PR }\end{array}$ & $\begin{array}{l}\text { Most common AEs: diarrhea } \\
(45 \%) \text {, hypertension ( } 40 \%) \text {, } \\
\text { nausea (37\%), stomatitis } \\
\text { (32\%), proteinuria }(26 \%) \text {, } \\
\text { and vomiting ( } 23 \%) \\
\text { Grade } 3 \text { AEs: hypertension } \\
\text { (I I\%) and proteinuria }(7 \%) \\
\text { Grade } 4 \text { AEs: } \\
\text { thrombocytopenia }(2 \%)\end{array}$ \\
\hline Molina et $\mathrm{al}^{36}$ & $\begin{array}{l}\text { Phase lb, dose-escalation, } \\
\text { multicenter, open-label } \\
\mathrm{n}=20 \\
\text { Patients with prior anti- } \\
\text { VEGF treatment }=17 \\
\text { Patients with prior mTOR- } \\
\text { targeted therapy }=7\end{array}$ & $\begin{array}{l}\text { Lenvatinib plus everolimus } \\
\text { Cohort I: lenvatinib } 12 \mathrm{mg} \\
\text { plus everolimus } 5 \mathrm{mg} \text { daily } \\
\text { Cohort 2: lenvatinib } 18 \mathrm{mg} \\
\text { plus everolimus } 5 \mathrm{mg} \text { daily } \\
\text { Cohort 3: lenvatinib } 24 \mathrm{mg} \\
\text { plus everolimus } 5 \mathrm{mg} \text { daily }\end{array}$ & $\begin{array}{l}\text { Cohort I and 2: } \\
\text { mPFS: } 330 \text { days } \\
\text { 6-month PFS rate: } 72.1 \% \\
\text { I2-month PFS rate: } 49.5 \% \\
\text { All cohorts: } \\
\text { DCR: } 80 \%\end{array}$ & $\begin{array}{l}\text { Most common AEs: fatigue } \\
(60 \%) \text {, mucosal inflammation } \\
(50 \%) \text {, diarrhea }(40 \%), \\
\text { hypertension ( } 40 \%) \text {, nausea } \\
(40 \%) \text {, proteinuria ( } 40 \%) \text {, } \\
\text { and vomiting ( } 40 \%) \\
\text { Grade 3-4 AEs: } \\
\text { hypertriglyceridemia ( } 15 \%) \text {, } \\
\text { proteinuria (I5\%), diarrhea } \\
\text { ( } 10 \%) \text {, and fatigue }(10 \%)\end{array}$ \\
\hline Motzer et $\mathrm{a}^{35}$ & $\begin{array}{l}\text { Phase II, randomized, } \\
\text { multicenter, open-label } \\
\mathrm{n}=153 \mathrm{mRCC} \text { patients who } \\
\text { progressed after I prior TKI }\end{array}$ & $\begin{array}{l}\text { Lenvatinib } 18 \mathrm{mg} \text { plus } \\
\text { everolimus } 5 \mathrm{mg} \text { daily } \\
(\mathrm{n}=5 \mathrm{I}) \\
\text { Lenvatinib } 24 \mathrm{mg} \text { daily } \\
(\mathrm{n}=52) \\
\text { Everolimus } 10 \mathrm{mg} \text { daily } \\
(\mathrm{n}=50)\end{array}$ & $\begin{array}{l}\text { mPFS: } \\
\text { Lenvatinib plus everolimus: } 14.6 \text { months } \\
\text { Lenvatinib alone: } 7.4 \text { months } \\
\text { Everolimus alone: } 5.5 \text { months } \\
\text { ORR: } \\
\text { Lenvatinib plus everolimus: } 43 \% \\
\text { Lenvatinib alone: } 27 \% \\
\text { Everolimus alone: } 6 \% \\
\text { mOS (updated analysis) } \\
\text { Lenvatinib plus everolimus: } 25.5 \text { months } \\
\text { Lenvatinib alone: } 19.1 \text { months } \\
\text { Everolimus alone: } 15.4 \text { months }\end{array}$ & $\begin{array}{l}\text { Discontinuation due to AEs: } \\
\text { Lenvatinib plus everolimus: } \\
24 \% \\
\text { Lenvatinib alone: } 25 \% \\
\text { Everolimus alone: } 12 \% \\
\text { Any grade AEs: } 100 \% \\
\text { Grade } 3 \text { or } 4 \text { AEs: } \\
\text { Lenvatinib plus everolimus: } \\
71 \% \\
\text { Lenvatinib alone: } 79 \% \\
\text { Everolimus alone: } 50 \%\end{array}$ \\
\hline
\end{tabular}

Abbreviations: VEGF, vascular endothelial growth factor; mTOR, mammalian target of rapamycin; mPFS, median progression-free survival; ORR, objective response rate; PFS, progression-free survival; PR, partial response; DCR, disease control rate; mOS, median overall survival; mRCC, metastatic renal cell cancer; TKI, tyrosine kinase inhibitor; $A E$, adverse event; $n$, number of patients. 
oral lenvatinib in a 2-week-on/1-week-off cycle, starting from a dose of $0.5 \mathrm{mg}$ bid, to assess the maximum tolerated dose (MTD). The MTD was determined to be $13 \mathrm{mg}$ bid, and observed dose-limiting toxicities (DLTs) included grade 3 aspartate aminotransferase/alanine aminotransferase increase and grade 3 platelet count decrease, according to Common Terminology Criteria for Adverse Events (CTCAE), version 3.0. Twenty-one patients (84\%) demonstrated stable disease (SD) as their best response to treatment, and one patient affected by metastatic colon cancer showed partial response (PR). ${ }^{27}$

A subsequent non-randomized, open-label, Phase I, doseescalation study supported clinical activity of lenvatinib in mRCC. Eighty-two patients affected by different histological types of solid tumors were enrolled. Lenvatinib was given on a continuous once-daily administration schedule. One cycle of treatment consisted of 28 days, and dose escalation was allowed after each cycle, starting from a dose of $0.2 \mathrm{mg}$ per day. The MTD was determined to be $25 \mathrm{mg}$ per day, and the most common adverse events (AEs) of any CTCAE version 4.0 grade included diarrhea (45\%), hypertension (40\%), nausea (37\%), stomatitis (32\%), proteinuria (26\%), and vomiting $(23 \%)$. Grade 3 hypertension and grade 3 proteinuria occurred in $11 \%$ and $7 \%$ of the overall population, respectively. Grade 4 thrombocytopenia was documented in $2 \%$ of patients. Seven patients ( $9 \%$ ) showed PR and 38 patients (46\%) displayed SD as their best response. Among the population affected by $\mathrm{mRCC}(\mathrm{n}=9[11 \%])$, four patients achieved a PR. In this cohort, the reported median progression-free survival (mPFS) was 447 days (95\% CI 279.0-559.0), and the extent of tumor reduction ranged from $5 \%$ (with lenvatinib $3.3 \mathrm{mg}$ ) to $55 \%$ (with lenvatinib $25 \mathrm{mg}$ ). ${ }^{28}$

The combination of lenvatinib plus everolimus for the treatment of $\mathrm{mRCC}$ progressed after VEGF-targeted therapy was first tested in a Phase Ib trial. Twenty patients were treated in sequential cohorts of escalating doses, starting from lenvatinib $12 \mathrm{mg}$ plus everolimus $5 \mathrm{mg}$ once daily (cohort 1), and increasing to lenvatinib $18 \mathrm{mg}$ plus everolimus $5 \mathrm{mg}$ once daily (cohort 2) up to lenvatinib $24 \mathrm{mg}$ plus everolimus $5 \mathrm{mg}$ once daily (cohort 3 ). Dose escalation was admitted after a 28-day treatment cycle without DLTs. The MTD was determined to be lenvatinib $18 \mathrm{mg}$ plus everolimus $5 \mathrm{mg}$ once daily, and the median number of treatment cycles was 5.5. The most common AEs of any grade were fatigue (60\%), mucosal inflammation (50\%), diarrhea (40\%), hypertension $(40 \%)$, nausea $(40 \%)$, proteinuria $(40 \%)$, and vomiting (40\%). Grade 3-4 toxicities were documented in $15 / 20$ patients $(75 \%)$ and they included hypertriglyceridemia
$(15 \%)$, proteinuria $(15 \%)$, diarrhea $(10 \%)$, and fatigue $(10 \%)$. Thirty percent of all patients had a PR as their best response (95\% CI 11.9-54.3), and disease control rate was achieved in $80 \%$ of patients across all cohorts. In cohorts 1 and 2 , the mPFS was 330 days (95\% CI 157-446); 6-month and 12-month PFS rates were $72.1 \%$ (95\% CI 48.8-95.4) and $49.5 \%$ (95\% CI 22.7-76.2), respectively. ${ }^{36}$

\section{Phase II evidence}

Consequent to the encouraging results of Phase I studies, a randomized, Phase II, open-label, multicenter trial by Motzer et al explored efficacy and safety of second-line treatment with lenvatinib alone or in combination with everolimus, compared to single-agent everolimus in the setting of mRCC. PFS was the primary endpoint, while toxicity, objective RR, and OS were secondary endpoints. One hundred and fiftythree patients with advanced ccRCC who progressed after one prior VEGF-targeted therapy were randomized 1:1:1 to receive single-agent lenvatinib (24 mg daily), single-agent everolimus (10 $\mathrm{mg}$ daily), or the combination (lenvatinib $18 \mathrm{mg}$ plus everolimus $5 \mathrm{mg}$ daily) in 28-day continuous cycles. Median treatment duration was 7.6 months for patients receiving the combination of both drugs, 7.4 months for those allocated to single-agent lenvatinib, and 4.1 months for those included in the single-agent everolimus arm.

Regarding the primary endpoint, mPFS was significantly improved by the combination therapy compared to singleagent everolimus (14.6 vs 5.5 months; hazard ratio [HR]: $0.40 ; 95 \%$ CI $0.24-0.68 ; P=0.0005)$. Single-agent lenvatinib also increased mPFS compared to single-agent everolimus (7.4 vs 5.5 months; HR: 0.61 ; 95\% CI 0.38-0.98; $P=0.048$ ). However, there was no statistically significant difference in terms of mPFS between the combination treatment and lenvatinib alone (HR: 0.66; 95\% CI 0.39-1.10; $P=0.12$ ), despite a favorable trend. ${ }^{35}$ Notably, the benefit in terms of PFS was confirmed by a blinded independent radiologic assessment. $^{37}$

Overall response rate (ORR) was $43 \%$ for patients receiving the combination therapy, compared to $6 \%$ for patients treated with everolimus alone (rate ratio 7.2; 95\% CI $2.3-22.5 ; P<0.0001)$; ORR was $27 \%$ for the single-agent lenvatinib arm, but data compared to those of the combination arm were not statistically significant (rate ratio 1.6; $95 \%$ CI $0.9-2.8 ; P=0.10)$. Conversely, the difference in terms of ORR between single-agent lenvatinib and single-agent everolimus was relevant and significant (rate ratio 4.5; 95\% CI 1.4-14.7; $P=0.0067$ ). Increase in median OS (mOS) for the combination arm was not significant at a primary data cutoff 
of the study, whereas the post hoc updated analysis showed an mOS of 25.5 months for lenvatinib plus everolimus, of 19.1 months for single-agent lenvatinib, and of 15.4 months for single-agent everolimus. In this updated analysis, the increase of mOS for the combination arm compared to single-agent everolimus was statistically significant $(25.5$ vs 15.4 months; HR: $0.51,95 \%$ CI $0.30-0.88 ; P=0.024)$. Nevertheless, mOS did not statistically differ between the single-agent lenvatinib arm and everolimus alone arm (19.1 vs 15.4 months; HR: 0.68 ; 95\% CI $0.41-1.14 ; P=0.12$ ) or combination arm (25.5 vs 19.1 months; HR: $0.75,95 \%$ CI $0.43-1.30 ; P=0.32)$.

In all, $71 \%$ of patients receiving lenvatinib plus everolimus and $62 \%$ of those assigned to lenvatinib alone required a lenvatinib dose reduction due to AEs. No unexpected drug toxicities were reported. The most frequently reported events were consistent with the class-specific AEs of the two molecules; treatment discontinuation due to AEs was observed in $24 \%$ of patients allocated to the lenvatinib plus everolimus arm, 25\% of patients who received lenvatinib, and $12 \%$ of patients assigned to everolimus. Grade 3-4 AEs occurred in $71 \%$ of patients receiving the combination, $79 \%$ for single-agent lenvatinib, and $50 \%$ for single-agent everolimus. Among these, the most common were diarrhea, fatigue, and hypertension for the first treatment arm; proteinuria, hypertension, and diarrhea for the second one; anemia, dyspnea, hypertriglyceridemia, and hyperglycemia for the third one.

Only one case of fatal drug-related AE (cerebral hemorrhage) was reported in the combination treatment arm; in the single-agent lenvatinib arm, one of three deaths due to AEs was supposed to be drug-related (myocardial infarction); no death in the single-agent everolimus arm was considered to be treatment-related.

Unfortunately, quality of life was not investigated in this study. ${ }^{35}$ Considering the positive results of the Phase II trial, lenvatinib received US FDA approval on May 13, 2016 for the treatment of advanced RCC after failure of prior TKI therapy at the dose of $18 \mathrm{mg} /$ daily in combination with everolimus $5 \mathrm{mg}$ /daily. The application for the EMA approval was announced by Eisai Co, Ltd in January $2016 .{ }^{38}$

\section{Discussion}

In Phase I and Phase II trials, lenvatinib has shown significant antitumor activity in $\mathrm{mRCC}$, and the combination of lenvatinib plus everolimus seems to be more effective than singleagent therapy. Lenvatinib is the only TKI which showed promising and relevant preclinical and clinical efficacy in combination with an mTOR inhibitor for the treatment of mRCC, with an acceptable toxicity profile.

The pivotal Phase II trial conducted by Motzer et al met its primary endpoint, mPFS, which is considered as a reasonable measure of outcome for a Phase II study. The trial was designed to have $70 \%$ power to detect a $50 \%$ improvement (HR 0.67) in PFS at a one-sided alpha level of 0.15 of the combination of the two drugs or single-agent lenvatinib compared to single-agent everolimus, assuming an mPFS of 5 months for everolimus and 7.5 months for each lenvatinibcontaining arm. The mPFS was improved by 9 months with the combination therapy compared to everolimus, with an HR significantly lower than preestablished (14.6 vs 5.5 months; HR: $0.40 ; 95 \%$ CI $0.24-0.68 ; P=0.0005) .{ }^{35}$ The independent radiologic assessment confirmed benefit in terms of PFS, strengthening the positive result. ${ }^{37}$ Moreover, outcome results of the control arm with single-agent everolimus were consistent with those obtained in previous studies investigating everolimus in second-line setting for $\mathrm{mRCC}$ after failure of previous TKIs, in terms of PFS, ORR, and OS. ${ }^{11,12,39}$ Regarding secondary endpoints, ORR was broadly larger for the combination regimen ( $43 \%$ vs $27 \%$ for single-agent lenvatinib and $6 \%$ for single-agent everolimus); OS also improved by the association of the two drugs, even if the result was not significant at primary data cutoff. Of note, patients enrolled in the study had overall characteristics similar to real life population, with a considerable portion of poor-risk patients (39\% according to the Memorial Sloan-Kettering Cancer Center risk status). ${ }^{35}$ Despite promising results on efficacy outcomes, the combination treatment appeared more toxic than single-agent everolimus, despite being no more toxic than single-agent lenvatinib, with a not-negligible incidence of grade 3-4 AEs (71\%) and one reported case of fatal drugrelated event in the combination arm, suggesting the need for optimization in the monitoring and treatment of AEs. The different toxicity profile of lenvatinib between the two arms may be due to the full dose administered in the single-agent arm $(24 \mathrm{mg})$ versus the reduced dose of the combination $\operatorname{arm}(18 \mathrm{mg})$. Of note, no unexpected treatment-related AEs were observed. ${ }^{35}$ Based on all these findings, with the limits of a Phase II open-label study, it is acceptable to consider these results as very relevant for their possible application in clinical practice. ${ }^{13}$

Moreover, the results of this randomized study clearly suggest that maintaining the suppression of VEGF pathway ("VEGF pressure") could represent a good therapeutic strategy after failure of first-line TKI treatment; in addition, the simultaneous blockade of the mTOR pathway seems to be 
definitely more efficient. ${ }^{40}$ The value of the "VEGF pressure" theory is further supported by the results of the METEOR study, a randomized Phase III trial in which cabozantinib, a novel TKI, obtained a better PFS than those of everolimus in mRCC patients who progressed after $\geq 1$ prior TKIs ( $7.4 \mathrm{vs}$ 3.8 months; HR: $0.51,95 \%$ CI $0.41-0.62 ; P<0.0001) .{ }^{11}$

Indeed, this cited trial currently represents the first and only controlled study with a direct comparison between the treatment sequence "TKI-mTOR inhibitor" and a "TKI-TKI strategy", the latter coming out as the winner.

Recently, the anti-PD-1 antibody nivolumab was approved by FDA and EMA for the treatment of mRCC in second-line setting. The pivotal trial CheckMate-025 showed an mOS improvement for patients who received nivolumab compared to those treated with everolimus ( 25.0 vs 19.6 months; HR: $0.75,98.5 \%$ CI $0.57-0.93 ; P=0.002$ ) with no significant difference in terms of mPFS (4.6 months for nivolumab vs 4.4 months for everolimus; HR: 0.88 , 95\% CI $0.75-1.03 ; P=0.11)$. This interesting finding has aroused hopes and has opened a new landscape for the treatment of mRCC, but on the other hand risking to obscure the value of a proven targeted therapy strategy, valuable at least for that fraction of patients primary refractory to immunotherapy (35\% in CheckMate-025 study). ${ }^{12}$ One of the next challenges will be identification of adequate predictive factors that could help the clinician to choose the best therapy/strategy (ie, TKI-TKI-nivolumab sequence vs TKI-nivolumab-TKI sequence vs TKI-TKI-TKI/mTOR inhibitor sequence vs TKI-TKI+mTOR-nivolumab sequence) for each patient. Until then, the high ORR obtained with lenvatinib plus everolimus combination (43\%) could suggest that patients with high disease burden or strongly symptomatic patients may be those most likely to benefit from this option.

Currently, a randomized, Phase III, three-arm trial is ongoing to compare the efficacy and safety of lenvatinib plus everolimus or of lenvatinib plus pembrolizumab versus sunitinib in first-line setting. ${ }^{41}$ The combination of lenvatinib plus everolimus is also being investigated in treatment-naive advanced non-ccRCC, in an ongoing Phase II trial. ${ }^{42}$

\section{Conclusion}

The combination therapy with lenvatinib plus everolimus is a promising choice for the treatment of mRCC patients who progress after first-line TKI treatment. It has been approved by the US FDA in this setting. Currently, use of either nivolumab or cabozantinib represents the new standard treatment in second-line setting; axitinib, everolimus, and sorafenib are still alternative options for selected patients.
Despite a not-negligible toxicity, lenvatinib plus everolimus showed improvement in PFS and high ORR; based on these findings, the combination therapy could be appropriate for patients with high disease burden or strongly symptomatic patients. Eventually, a Phase III study is needed to validate the encouraging results of the Phase II trial.

\section{Disclosure}

The authors report no conflicts of interest in this work.

\section{References}

1. Ljungberg B, Albiges L, Bensalah K, et al. European Association of Urology guidelines on renal cell carcinoma; 2017. Available from: http:// uroweb.org/guideline/renal-cell-carcinoma. Accessed April 20, 2017.

2. Escudier B, Porta C, Schmidinger M, et al. Renal cell carcinoma: ESMO clinical practice guidelines for diagnosis, treatment and follow-up. Ann Oncol. 2014;25(Suppl 3):49-56.

3. Rini BI, Campbell SC, Escudier B. Renal cell carcinoma. Lancet. 2009;373(9669):1119-1132.

4. Lam JS, Leppert JT, Belldegrun AS, Figlin RA. Novel approaches in the therapy of metastatic renal cell carcinoma. World J Urol. 2005; 23(3):202-212.

5. Choueiri TK, Motzer RJ. Systemic therapy for metastatic renal-cell carcinoma. N Engl J Med. 2017;376(4):354-366.

6. Buti S, Leonetti A, Dallatomasina A, Bersanelli M. Everolimus in the management of metastatic renal cell carcinoma: an evidence-based review of its place in therapy. Core Evid. 2016;11:23-36.

7. Mendel DB, Laird AD, Xin X, et al. In vivo antitumor activity of SU11248, a novel tyrosine kinase inhibitor targeting vascular endothelial growth factor and platelet-derived growth factor receptors: determination of a pharmacokinetic/pharmacodynamic relationship. Clin Cancer Res. 2003;9(1):327-337.

8. Sloan B, Scheinfeld NS. Pazopanib, a VEGF receptor tyrosine kinase inhibitor for cancer therapy. Curr Opin Investig Drugs. 2008;9(12): 1324-1335.

9. Hu-Lowe DD, Zou HY, Grazzini ML, et al. Nonclinical antiangiogenesis and antitumor activities of axitinib (AG-013736), an oral, potent, and selective inhibitor of vascular endothelial growth factor receptor tyrosine kinases 1, 2, 3. Clin Cancer Res. 2008;14(22):7272-7283.

10. Wilhelm SM, Carter C, Tang L, et al. BAY 43-9006 exhibits broad spectrum oral antitumor activity and targets the RAF/MEK/ERK pathway and receptor tyrosine kinases involved in tumor progression and angiogenesis. Cancer Res. 2004;64(19):7099-7109.

11. Choueiri TK, Escudier BJ, Powles T, et al. Cabozantinib versus everolimus in advanced renal cell carcinoma (METEOR): final results from a randomised, open-label, phase 3 trial. Lancet Oncol. 2016;17(7):917-927.

12. Motzer RJ, Escudier B, McDermott DF, et al; CheckMate 025 Investigators. Nivolumab versus everolimus in advanced renal-cell carcinoma. N Engl J Med. 2015;373(19):1803-1813.

13. NCCN clinical practice guidelines in oncology: kidney cancer (version 2.2017). Available from: https://www.nccn.org/professionals/ physician_gls/pdf/kidney.pdf. Accessed May 20, 2017.

14. Banumathy G, Cairns P. Signaling pathways in renal cell carcinoma. Cancer Biol Ther. 2010;10(7):658-664.

15. Hickey MM, Simon MC. Regulation of angiogenesis by hypoxia and hypoxia-inducible factors. Curr Top Dev Biol. 2006;76:217-257.

16. Gudas LJ, Fu L, Minton DR, Mongan NP, Nanus DM. The role of HIF $1 \alpha$ in renal cell carcinoma tumorigenesis. J Mol Med (Berl). 2014; 92(8):825-836.

17. Katso R, Okkenhaug K, Ahmadi K, White S, Timms J, Waterfield MD. Cellular function of phosphoinositide 3-kinases: implications for development, immunity, homeostasis, and cancer. Annu Rev Cell Dev Biol. 2001;17:615-675. 
18. Bernardi R, Guernah I, Jin D, et al. PML inhibits HIF-1 $\alpha$ translation and neoangiogenesis through repression of mTOR. Nature. 2006;442(7104):779-785.

19. Toschi A, Lee E, Gadir N, Ohh M, Foster DA. Differential dependence of hypoxia-inducible factors $1 \alpha$ and $2 \alpha$ on mTORC1 and mTORC2. J Biol Chem. 2008;283(50):34495-34499.

20. Guo H, German P, Bai S, et al. The PI3K/AKT pathway and renal cell carcinoma. J Genet Genomics. 2015;42(7):343-353.

21. Ravaud A, Barrios CH, Alekseev B, et al. RECORD-2: phase II randomized study of everolimus and bevacizumab versus interferon $\alpha-2 \mathrm{a}$ and bevacizumab as first-line therapy in patients with metastatic renal cell carcinoma. Ann Oncol. 2015;26(7):1378-1384.

22. Flaherty KT, Manola JB, Pins M, et al. BEST: a randomized phase II study of vascular endothelial growth factor, RAF kinase, and mammalian target of rapamycin combination targeted therapy with bevacizumab, sorafenib, and temsirolimus in advanced renal cell carcinoma - a trial of the ECOG-ACRIN Cancer Research Group (E2804). J Clin Oncol. 2015;33(21):2384-2391.

23. Rini B, Bellmunt J, Clancy J, et al. Randomized phase III trial of temsirolimus and bevacizumab versus interferon alfa and bevacizumab in metastatic renal cell carcinoma: INTORACT trial. J Clin Oncol. 2014;32(8):752-759.

24. Okamoto K, Kodama K, Takase K, et al. Antitumor activities of the targeted multi-tyrosine kinase inhibitor lenvatinib (E7080) against RET gene fusion-driven tumor models. Cancer Lett. 2013;340(1):97-103.

25. Sonpavde G, Willey CD, Sudarshan S. Fibroblast growth factor receptors as therapeutic targets in clear-cell renal cell carcinoma. Expert Opin Investig Drugs. 2014;23(3):305-315.

26. Matsuki M, Adachi Y, Ozawa Y, et al. Targeting of tumor growth and angiogenesis underlies the enhanced antitumor activity of lenvatinib in combination with everolimus. Cancer Sci. 2017;108(4):763-771.

27. Yamada K, Yamamoto N, Yamada Y, et al. Phase I dose-escalation study and biomarker analysis of E7080 in patients with advanced solid tumors. Clin Cancer Res. 2011;17(8):2528-2537.

28. Boss DS, Glen H, Beijnen JH, et al. A phase I study of E7080, a multitargeted tyrosine kinase inhibitor, in patients with advanced solid tumours. Br J Cancer. 2012;106(10):1598-1604.

29. Gupta A, Jarzab B, Capdevila J, Shumaker R, Hussein Z. Population pharmacokinetic analysis of lenvatinib in healthy subjects and patients with cancer. Br J Clin Pharmacol. 2016;81(6):1124-1133.

30. Dubbelman AC, Rosing H, Nijenhuis C, et al. Pharmacokinetics and excretion of (14)C-lenvatinib in patients with advanced solid tumors or lymphomas. Invest New Drugs. 2015;33(1):233-240.

31. Hussein Z, Mizuo H, Hayato S, Namiki M, Shumaker R. Clinical pharmacokinetic and pharmacodynamic profile of lenvatinib, an orally active, small-molecule, multitargeted tyrosine kinase inhibitor. Eur J Drug Metab Pharmacokinet. Epub 2017 Feb 24.
32. Shumaker RC, Aluri J, Fan J, Martinez G, Thompson GA, Ren M. Effect of rifampicin on the pharmacokinetics of lenvatinib in healthy adults. Clin Drug Investig. 2014;34(9):651-659.

33. Shumaker R, Aluri J, Fan J, Martinez G, Thompson GA, Ren M. Effects of ketoconazole on the pharmacokinetics of lenvatinib (E7080) in healthy participants. Clin Pharmacol Drug Dev. 2015;4(2):155-160.

34. Shumaker R, Aluri J, Fan J, Martinez G, Pentikis H, Ren M. Influence of hepatic impairment on lenvatinib pharmacokinetics following singledose oral administration. J Clin Pharmacol. 2015;55(3):317-327.

35. Motzer RJ, Hutson TE, Glen H, et al. Lenvatinib, everolimus, and the combination in patients with metastatic renal cell carcinoma: a randomized, phase 2, open-label, multicenter trial. Lancet Oncol. 2015; 16:1473-1482.

36. Molina AM, Hutson TE, Larkin J, et al. A phase $1 \mathrm{~b}$ clinical trial of the multi-targeted tyrosine kinase inhibitor lenvatinib (E7080) in combination with everolimus for treatment of metastatic renal cell carcinoma (RCC). Cancer Chemother Pharmacol. 2014;73(1):181-189.

37. Motzer RJ, Hutson TE, Ren M, Dutcus C, Larkin J. Independent assessment of lenvatinib plus everolimus in patients with metastatic renal cell carcinoma. Lancet Oncol. 2016;17(1):e4-e5.

38. EISAI. Eisai submits new application in Europe for in-house developed anticancer agent lenvatinib seeking approval for indication covering renal cell carcinoma. Available from: www.eisai.com/news/ news201602.html. Accessed April 20, 2017.

39. Motzer RJ, Escudier B, Oudard S, et al; RECORD-1 Study Group. Efficacy of everolimus in advanced renal cell carcinoma: a doubleblind, randomised, placebo-controlled phase III trial. Lancet. 2008; 372(9637):449-456.

40. Buti S, Bersanelli M. Combination therapy in kidney cancer: the next revolution? Lancet Oncol. 2015;16(15):1441-1442.

41. Eisai Inc. Lenvatinib/Everolimus or Lenvatinib/Pembrolizumab Versus Sunitinib Alone as Treatment of Advanced Renal Cell Carcinoma. Available from: https:/clinicaltrials.gov/ct2/show/NCT02811861. NLM identifier: NCT02811861. Accessed April 20, 2017.

42. Eisai Inc. A Phase 2 Trial to Evaluate Efficacy and Safety of Lenvatinib in Combination With Everolimus in Subjects With Unresectable Advanced or Metastatic Non Clear Cell Renal Cell Carcinoma (nccRCC) Who Have Not Received Any Chemotherapy for Advanced Disease. Available from: https://clinicaltrials.gov/ct2/show/NCT02915783. NLM identifier: NCT02915783. Accessed April 20, 2017.
Therapeutics and Clinical Risk Management

\section{Publish your work in this journal}

Therapeutics and Clinical Risk Management is an international, peerreviewed journal of clinical therapeutics and risk management, focusing on concise rapid reporting of clinical studies in all therapeutic areas, outcomes, safety, and programs for the effective, safe, and sustained use of medicines. This journal is indexed on PubMed Central, CAS,

\section{Dovepress}

EMBase, Scopus and the Elsevier Bibliographic databases. The manuscript management system is completely online and includes a very quick and fair peer-review system, which is all easy to use. Visit $\mathrm{http}: / / \mathrm{www}$.dovepress.com/testimonials.php to read real quotes from published authors. 